\title{
Advance Care Planning in an Accountable Care Organization Is Associated with Increased Advanced Directive Documentation and Decreased Costs
}

\author{
William F. Bond, MD, MS, ${ }^{1-3}$ Minchul Kim, $\mathrm{PhD}^{4,5}$ Chris M. Franciskovich, MS, \\ Jason E. Weinberg, MS, Jessica D. Svendsen, BA, CRCC, ${ }^{1}$ Linda S. Fehr, RN, BSN, CPHQ? \\ Amy Funk, RN, PhD, Robert Sawicki, MD, and Carl V. Asche, MBA, MSc, PhD ${ }^{4,5}$
}

\begin{abstract}
Background: Advance care planning (ACP) documents patient wishes and increases awareness of palliative care options.

Objective: To study the association of outpatient ACP with advanced directive documentation, utilization, and costs of care.

Design: This was a case-control study of cases with ACP who died matched 1:1 with controls. We used 12 months of data pre-ACP/prematch and predeath. We compared rates of documentation with logit model regression and conducted a difference-in-difference analysis using generalized linear models for utilization and costs.

Setting/subjects: Medicare beneficiaries attributed to a large rural-suburban-small metro multisite accountable care organization from January 2013 to April 2016, with cross reference to ACP facilitator logs to find cases. Measurements: The presence of advance directive forms was verified by chart review. Cost analysis included all utilization and costs billed to Medicare.

Results: We matched 325 cases and 325 controls (51.1\% female and 48.9\% male, mean age 81). 320/325 (98.5\%) ACP versus 243/325 (74.8\%) of controls had a Healthcare Power of Attorney (odds ratio [OR] 21.6, 95\% CI 8.6-54.1) and 172/325(52.9\%) ACP versus 145/325 (44.6\%) controls had Practitioner Orders for Life Sustaining Treatment (OR 1.40, 95\% CI 1.02-1.90) post-ACP/postmatch. Adjusted results showed ACP cases had fewer inpatient admissions $(-0.37$ admissions, $95 \%$ CI -0.66 to -0.08 ), and inpatient days ( -3.66 days, $95 \%$ CI -6.23 to -1.09 ), with no differences in hospice, hospice days, skilled nursing facility use, home health use, 30-day readmissions, or emergency department visits. Adjusted costs were $\$ 9,500$ lower in the ACP group (95\% CI $-\$ 16,207$ to $-\$ 2,793$ ).

Conclusions: ACP increases documentation and was associated with a reduction in overall costs driven primarily by a reduction in inpatient utilization. Our data set was limited by small numbers of minorities and cancer patients.
\end{abstract}

Keywords: advance care planning; advance directives; healthcare costs; healthcare utilization; healthcare power of attorney; practitioner orders for life sustaining treatment

\footnotetext{
${ }^{1}$ Jump Simulation, OSF HealthCare, Peoria, Illinois.

${ }^{2}$ Department of Emergency Medicine, OSF HealthCare, Peoria, Illinois.

${ }^{3}$ Department of Emergency Medicine, University of Illinois College of Medicine at Peoria, Peoria, Illinois.

${ }^{4}$ Center for Outcomes Research, University of Illinois College of Medicine at Peoria, Peoria, Illinois.

${ }^{5}$ Department of Internal Medicine, University of Illinois College of Medicine at Peoria, Peoria, Illinois.

${ }^{6}$ Division of Healthcare Analytics, OSF HealthCare, Peoria, Illinois.

${ }^{7}$ Division of Supportive Care, OSF HealthCare, Peoria, Illinois.

${ }^{8}$ College of Nursing, Illinois Wesleyan University, Bloomington, Illinois.

Accepted November 7, 2017.
}

(C) William F. Bond et al., 2017; Published by Mary Ann Liebert, Inc. This Open Access article is distributed under the terms of the Creative Commons Attribution Noncommercial License (http://creativecommons.org/licenses/by-nc/4.0/) which permits any noncommercial use, distribution, and reproduction in any medium, provided the original author(s) and the source are credited. 


\section{Introduction}

$\mathbf{T}$ He Institute of Medicine RePoRT, Dying in America, calls for more palliative and advance care planning (ACP) services in the U.S. healthcare system. ${ }^{1}$ These services can lead to more appropriate care with better symptom relief at a lower cost. ${ }^{2,3}$ However, there is often a lack awareness of these services ${ }^{4}$ and patients are frequently too ill to make decisions for themselves near the end of life. ${ }^{5}$

ACP allows patients and families to consider and express preferences for care commensurate with their values through a facilitated discussion that is intended to be updated as circumstances change., 6 ACP may be part of a broader palliative care delivery model ${ }^{8,9}$ and having an ACP increases the likelihood that individuals' wishes will be known, documented, and followed. ${ }^{10,11}$ ACP increases the quality of care $^{12}$ and can reduce caregiver stress, depression, and anxiety. ${ }^{13}$ The discussion is often facilitated by interprofessional team members, with physicians providing input on prognosis and treatment options. We expect increased physician engagement because the Center for Medicare and Medicaid Services (CMS) created provider billing options for ACP in January of $2016 .^{14}$

ACP usually includes completing or reviewing the Healthcare Power of Attorney (HCPOA) document. If appropriate, a Practitioner Orders for Life Sustaining Treatment (POLST) document may be completed, which clarifies wishes for resuscitation, crosses home and healthcare settings, and can be translated into inpatient code status orders with patient affirmation. ACP may make it more likely that a POLST form is completed. ${ }^{15}$ The ACP discussion record itself does not suggest any particular choices within the HCPOA or POLST, and is not a medical order, but it gives families, surrogate decision makers, and healthcare providers a record of patients' preferences and values for informed choices as disease and age progress. ACP may lead to the often expressed goal of more patients dying outside of the hospital setting. ${ }^{12,16-18}$

With regard to costs, inpatient palliative care consultation has shown benefits in both costs and utilization. ${ }^{19,20}$ While newer as a care delivery model, outpatient palliative care has also shown reduced costs of care. ${ }^{21-25}$ The impact of earlier use of hospice services on costs has been mixed. ${ }^{26-28}$ Minimal data exist regarding the impact of outpatient ACP on costs and utilization from a system perspective, including inpatient and outpatient costs. Also, studies have been heterogeneous in the patient populations and disease groupings studied, and the costs considered. ${ }^{29}$

We examined the association of outpatient ACP with advance directive documentation rates, utilization, and costs in a cohort of patients who died compared to matched controls using accountable care organization (ACO) data. Our ACO made considerable investments in the ACP process to improve access, including efforts to improve the number and qualifications of ACP facilitators, over the time period 2008 to present.

\section{Methods}

We conducted a case-control study with patients with ACP serving as cases, and those without ACP serving as matched controls using three data sources: (1) ACO data, (2) an ACP facilitator logging database (Instant Data Entry Application [IDEA] v4.4; Health Catalyst ${ }^{\circledR}$, Salt Lake City, UT), and (3) EPIC $^{\odot}$ Electronic Medical Record (EMR) data. This study was approved by the regional institutional review board and we received permission from CMS to use our ACO data for research purposes.

The ACO data covered January 2013 to the end of April 2016. The ACO is multisite healthcare system serving a catchment area of nearly 3 million people that includes 11 hospitals, 75 outpatient practices, and more than 18,000 employees. During the study period, the system maintained over 150 active ACP facilitators. For plan years 2013-2016, there were $34,339,36,463,40,605$, and 48,185 patients, respectively, considered attributed to the ACO. Data included individuals who received the majority of their care from our system as determined by an attribution algorithm used by CMS. $^{30}$

The IDEA ACP facilitator logging database is a webbased, external to the health record, HIPAA-compliant system used by ACP facilitators to log their ACP discussions. All facilitators are trained in how to log during a day-long course on facilitation that includes didactics, and from 2015 onward, included simulation with standardized patient actors. ${ }^{31}$

The ACP discussion record completed collaboratively by the facilitator and patient/family, along with separate files for HCPOA and/or POLST if generated, is scanned into the EPIC EMR and placed under the advanced directives $(A D)$ tab. The EMR thus served as the source for notification in the dataset that a record of some kind was present under the AD tab. The EMR also provided the problem list and comorbidities that fed the matching algorithm, as well as the presence or absence of inpatient palliative care consultations.

Cases with ACP were found by cross-referencing the ACO data with the ACP logging database (Fig. 1). We used a 1:1 matching algorithm (Appendix Fig. 1) based on following variables: ACP date with the snapshot index date for controls, gender, race, age, Deyo adaptation of the Charlson Comorbidity Index (CCI), ${ }^{32}$ and an internally developed utilization risk score (similar to Medicare's Hierarchical Condition Categories model). This study's matching approach is further described in Appendix Figure 2.

Outcome variables included the presence of HCPOA and POLST forms, healthcare costs, and utilization. HCPOA and POLST forms were chosen because the presence of these forms illustrates documentation of patient surrogate decision makers and preferences. We began with the assumption that many ADs could come from outside the ACP process. Patients could have the following: no ADs, ADs completed outside of our system and scanned in, ADs completed in our system, but outside of the ACP process, or ADs completed as part of our system's ACP process.

We reviewed all charts to note the types of ADs and relevant preferences for future study, with adjudication of unclear items by appropriate coauthors (W.B., L.F.). Three cases in the ACP group were eliminated (two cases: no documentation of an ACP discussion, and one case: ACP discussion on admission to hospice). One case in the control group was eliminated for no log data and an older (2009) 


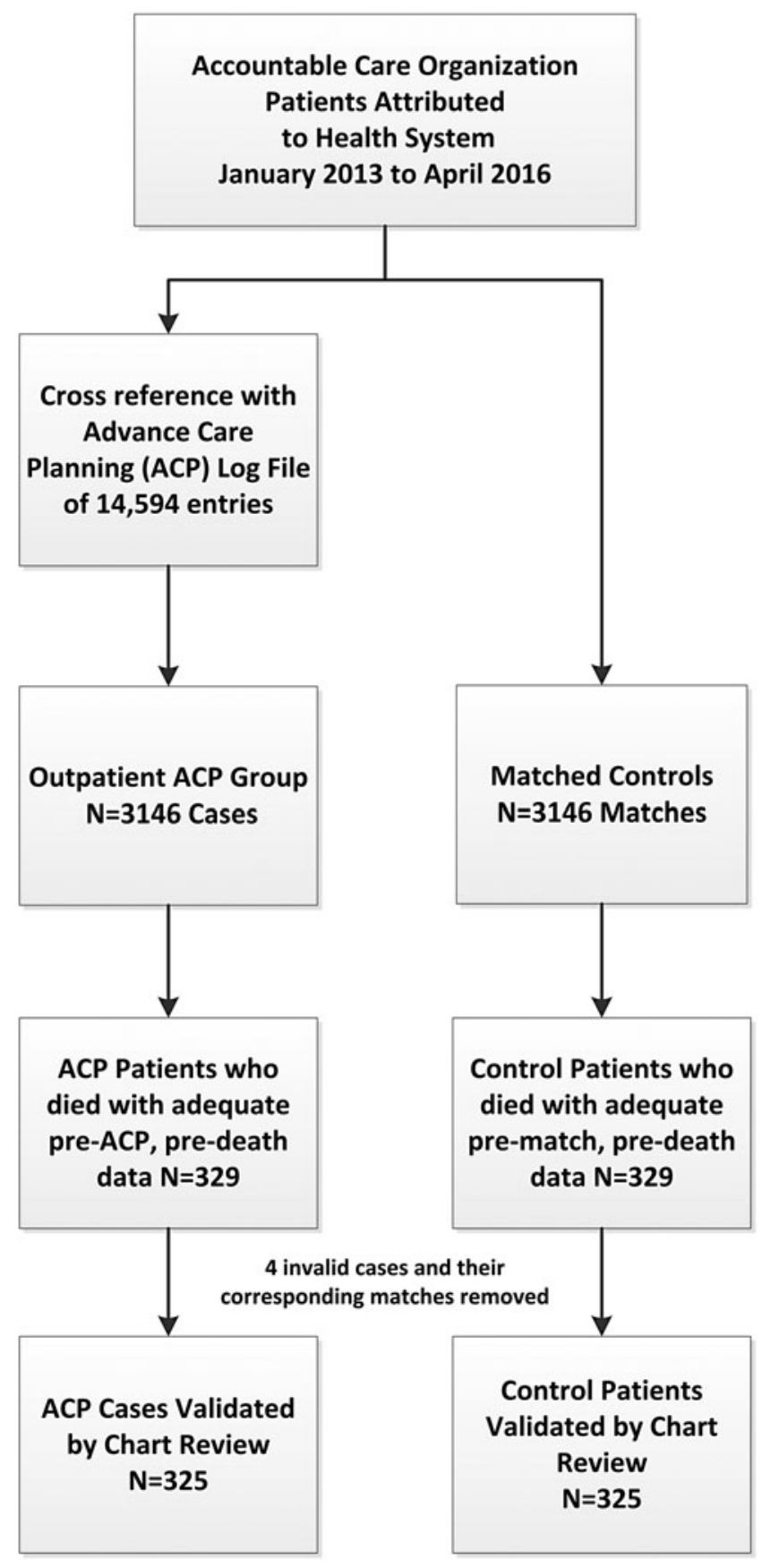

FIG. 1. Patient cohort selection and matching.

ACP discussion form (improper group assignment). All corresponding matches from excluded charts were excluded in the analysis.

The healthcare cost and utilization data included total healthcare expenditure, emergency department (ED) visits, hospital admission counts, readmissions by CMS definition, hospital days, ICU use count, ICU days, hospice use count, and hospice days. These variables were from the ACO dataset that included all claims paid by Medicare incurred inside or outside our system. We included all age groups insured by Medicare, because Medicare beneficiaries younger than 65 years of age may benefit significantly from ACP and may be high utilizers of healthcare services. Total expenditure included all Medicare payments.

\section{Statistical analysis}

Demographic summaries are presented with mean and standard deviation for continuous variables, and with frequency and percentage for categorical variables. Continuous variables were compared with unpaired $t$-tests and categorical variables with Chi-squared tests. For HCPOA and POLST presence, we employed a logit model adjusted for age, gender, race, CMS risk score, and comorbidities (congestive heart failure [CHF], Chronic Obstructive Pulmonary Disease [COPD], end-stage renal disease, and cancer). For utilization and cost, we performed a difference-in-difference analysis using a generalized linear model with log link and gamma distribution (expenditure), or Poisson distribution (utilizations) adjusted for above covariates. As the ACP group was slightly more ill than the control group even after matching, a difference-in-difference method was employed to remove this effect on utilization and cost. We collected utilization and cost data for the 12-month period before ACP date and 12-month period before death date. For those who did not have a full 12-month period between ACP date and death date (total $n=190$ and each group $n=95$ ), we used a multiple imputation method to fill out outcome variables. Ten imputed values were obtained for each missing observation with the mean used for the missing value. All costs were converted to 2016 U.S. dollars using Medical Component of Consumer Price Index. Since the number of patients with imputed observations was higher than initially anticipated (29\% of all sample), sensitivity analyses were conducted for internal validity (1) using only existing data (removing imputed data) and (2) using six-month data for all samples without imputation method. A statistical significance level of 0.05 was set for all hypothesis tests. All analyses were conducted using Stata $^{\circledR}$ version 12 (StataCorp, College Station, TX).

A return on investment (ROI) was calculated based on ACP intervention cost and its benefit to Medicare expenditure. ACP intervention cost added program start-up costs, maintenance administration costs, education costs for facilitator training, and the costs of time the facilitator spent with the patient. We assumed one hour of time to facilitate the discussion with salary cost of the facilitator taken as a weighted average of the interprofessional facilitators.

\section{Results}

We matched 325 cases and 325 controls $(51.1 \%$ female and $48.9 \%$ male, mean age 81 ). Demographics, including urban/rural categories, as well as comorbidities are listed in Table 1. The ACP group had a slightly higher CCI and predicted utilization risk. The ACP group also had a slightly higher proportion of patients with CHF $51.7 \%$ vs. $44 \%(p=0.05)$, and a higher proportion of patients with COPD $61.5 \%$ versus $53.2 \%(p=0.032)$. We noted a statistically significant difference in the distribution of rural urban codes (see Table 1 for details).

In the 12 months before death, the ACP group had a higher proportion of HCPOA completed and captured in the EMR: $320 / 325(98.5 \%)$ compared to the control group 243/325 (74.8\%) (odds ratio [OR]: 21.6, 95\% CI 8.6-54.1, $p<0.001$ ). In addition, the ACP group had a higher proportion of POLST 
Table 1. Demographics

\begin{tabular}{|c|c|c|c|}
\hline \multicolumn{2}{|l|}{ Continuous variables } & \multirow{2}{*}{$\begin{array}{c}A C P(\mathrm{~N}=325) \\
81.13(8.54)\end{array}$} & \multirow{2}{*}{$\begin{array}{c}\text { Match }(\mathrm{N}=325) \\
81.18(8.19)\end{array}$} \\
\hline age & Mean (SD) & & \\
\hline CMS risk score ${ }^{\mathrm{a}}$ & Mean (SD) & $1.91(1.16)$ & $1.68(1.12)$ \\
\hline Predicted utilization rank & Mean (SD) & $0.69(0.25)$ & $0.66(0.25)$ \\
\hline CCI & Mean (SD) & $9.36(2.95)$ & $9.13(2.68)$ \\
\hline Categorical variables & & $\mathrm{N}(\%)$ & $\mathrm{N}(\%)$ \\
\hline \multirow[t]{2}{*}{ Gender, $N(\%)$} & $0:$ Female & $166(51.1)$ & $166(51.1)$ \\
\hline & 1:Male & $159(48.9)$ & $159(48.9)$ \\
\hline \multirow[t]{2}{*}{ Race, $N(\%)$} & 1:White or Caucasian & $319(98.2)$ & $319(98.2)$ \\
\hline & 2:Black & $6(1.8)$ & $6(1.8)$ \\
\hline \multirow[t]{2}{*}{$\mathrm{CHF}, N(\%)^{\mathrm{b}}$} & $0: \mathrm{No}$ & $157(48.3)$ & $182(56.0)$ \\
\hline & $1:$ Yes & $168(51.7)$ & $143(44.0)$ \\
\hline \multirow[t]{2}{*}{ COPD, $N(\%)^{\mathrm{c}}$} & $0: \mathrm{No}$ & $125(38.5)$ & $152(46.8)$ \\
\hline & $1:$ Yes & $200(61.5)$ & $173(53.2)$ \\
\hline \multirow[t]{2}{*}{ Cancer, $N(\%)$} & $0: \mathrm{No}$ & $318(97.8)$ & $315(96.9)$ \\
\hline & $1:$ Yes & $7(2.2)$ & $10(3.1)$ \\
\hline \multirow[t]{2}{*}{$\mathrm{ESRD}, N(\%)$} & $0: \mathrm{No}$ & $185(56.9)$ & $201(61.8)$ \\
\hline & $1:$ Yes & $140(43.1)$ & $124(38.2)$ \\
\hline Medicare beneficiary & 1:Aged without ESRD & $307(94.5)$ & $314(96.6)$ \\
\hline \multirow[t]{3}{*}{ entitlement reason, $N(\%)$} & 2:Aged with ESRD & $13(4.0)$ & $8(2.5)$ \\
\hline & 3:Disabled without ESRD & $4(1.2)$ & $3(0.9)$ \\
\hline & 4:ESRD only & $1(0.3)$ & $0(0.0)$ \\
\hline \multirow[t]{8}{*}{$\begin{array}{l}\text { USDA rural-urban } \\
\quad \text { continuum codes, } N(\%)^{\mathrm{d}}\end{array}$} & $\begin{array}{l}\text { 1:Metro: counties in metro areas } \\
\text { of } 1 \text { million population or more }\end{array}$ & $15(4.6)$ & $11(3.4)$ \\
\hline & $\begin{array}{l}\text { 2: Metro: counties in metro areas } \\
\text { of } 250,000 \text { to } 1 \text { million population }\end{array}$ & $144(44.3)$ & $157(48.3)$ \\
\hline & $\begin{array}{l}\text { 3: Metro: counties in metro areas } \\
\text { of fewer than } 250,000 \text { population }\end{array}$ & $92(28.3)$ & $54(16.6)$ \\
\hline & $\begin{array}{l}\text { 4: Nonmetro: urban population of } 20,000 \text { or more, } \\
\text { adjacent to a metro area }\end{array}$ & $59(18.2)$ & $77(23.7)$ \\
\hline & $\begin{array}{l}\text { 5: Nonmetro: urban population of } 20,000 \text { or more, } \\
\text { not adjacent to a metro area }\end{array}$ & $0(0.0)$ & $1(0.3)$ \\
\hline & $\begin{array}{l}\text { 6: Nonmetro: urban population of } 2500 \text { to } 19,999 \text {, } \\
\text { adjacent to a metro area }\end{array}$ & $15(4.6)$ & $18(5.5)$ \\
\hline & $\begin{array}{l}\text { 7: Nonmetro: urban population of } 2500 \text { to } 19,999 \text {, } \\
\text { not adjacent to a metro area }\end{array}$ & $0(0.0)$ & $3(0.9)$ \\
\hline & $\begin{array}{l}\text { 8: Nonmetro: completely rural or less than } 2500 \\
\text { urban population, adjacent to a metro area }\end{array}$ & $0(0.0)$ & $4(1.2)$ \\
\hline
\end{tabular}

Statistically significant differences are noted by references to footnotes.

${ }^{\mathrm{a}} \mathrm{We}$ found significant differences in the CMS risk score $(p=0.01$, t-test).

${ }^{\mathrm{b}} \mathrm{We}$ found significant differences in the CHF proportion $(p=0.05$, Chi-squared).

${ }^{\mathrm{c}} \mathrm{We}$ found significant differences in the COPD proportion $(p=0.03$, Chi-squared).

${ }^{\mathrm{d}}$ We found significant differences in the USDA Rural-Urban Continuum Codes $(p=0.003$, Chi-squared).

ACP, advance care planning; CMS, Center for Medicare and Medicaid Services; CCI, Charlson Comorbidity Index; CHF, congestive heart failure; COPD, chronic obstructive pulmonary disease; ESRD, end-stage renal disease; USDA, United States Department of Agriculture.

completed and captured in the EMR: 172/325 (52.9\%) compared to the control group 145/325 (44.6\%) (OR: 1.40, 95\% CI 1.02-1.90, $p=0.034$ ). (See Appendix Fig. 3.) Adjusted results were similar with an odds ratio of 22.6 for HCPOA and 1.39 for POLST.

Total costs for both time periods, both unadjusted and adjusted, are presented in Figure 2. Detailed utilization and cost information are presented in Table 2. With regard to utilization, adjusted results showed ACP cases had fewer inpatient admissions $(-0.37,95 \% \mathrm{CI}-0.66$ to -0.08$)$, and fewer inpatient days $(-3.66,95 \% \mathrm{CI}-6.23$ to -1.09$)$, with no differences in hospice use, hospice days, skilled nursing facility use, home health use, 30-day readmissions, or ED visits. Overall adjusted costs were $\$ 9,500$ lower in the ACP group (95\% CI $-\$ 16,207$ to $-\$ 2,793$ ).

Results of the sensitivity analyses were consistent with Table 2. The first sensitivity analysis (Appendix Table 1) was a balanced subsample ( $n=230$ in each group) with removal of imputed values and found that overall adjusted annual costs were $\$ 10,433$ lower in the ACP group $(95 \%$ CI $-\$ 18,467-$ $\$ 2,398)$. The second sensitivity analysis, also without imputed values, used the entire sample but included six months of data pre-ACP, prematch, and six months predeath (Appendix Table 2). Six-month adjusted costs were also $\$ 5,002$ lower in the ACP group, although this was not statistically significant (95\% CI $-\$ 10,158$ to $\$ 155)$. 

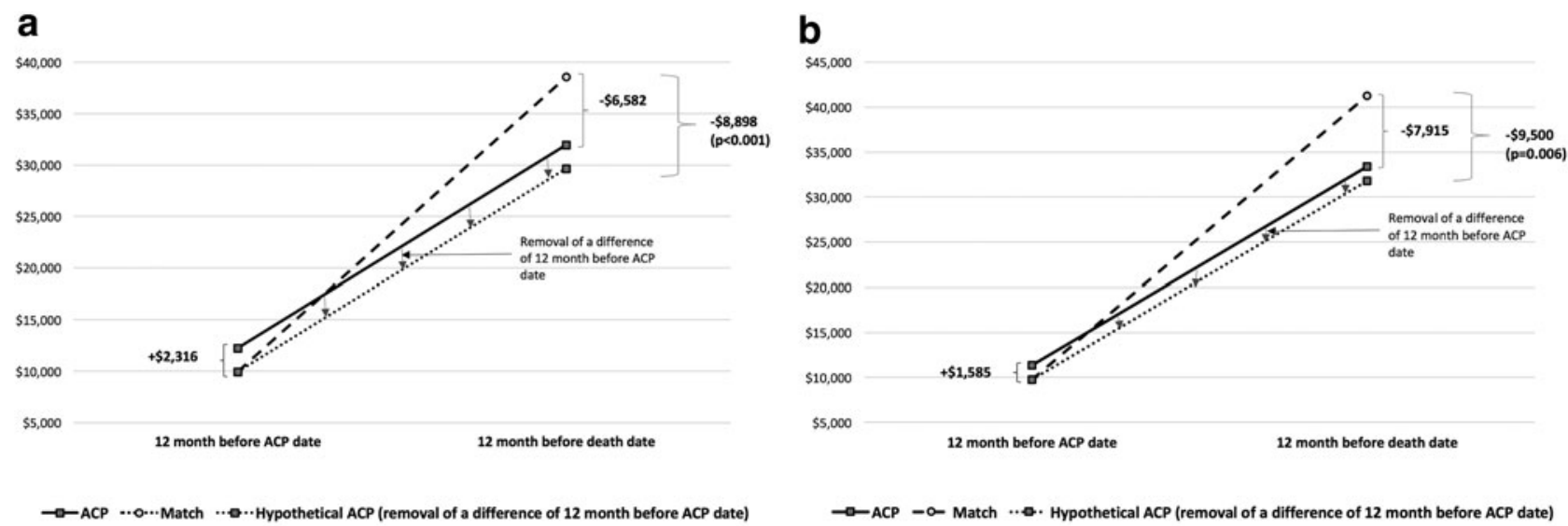

FIG. 2. Cost comparison. Costs were compared with a difference-in-difference method, using a generalized linear model with gamma distribution for expenditures (a) and a generalized linear model with gamma distribution adjusted by age, gender, race, CMS risk score, and comorbidities (CHF, COPD, ESRD, and cancer) (b). All expenditures were converted to 2016 U.S. dollars using the Medical Component of the Consumer Price Index. For patients $(N=190$ and each group $N=95)$ who do not have a full 12month period between ACP date and death date, we used a multiple imputation method. Ten imputed values were obtained for each missing observation with the mean used for the missing value. ACP, advance care planning; CHF, congestive heart failure; CMS, Center for Medicare and Medicaid Services; COPD, Chronic Obstructive Pulmonary Disease; ESRD, end-stage renal disease.

We found no statistical difference in inpatient palliative consultation rates between ACP 98/325 (30\%) versus controls $82 / 325$ (25\%) (difference $4.9 \%, 95 \% \mathrm{CI}-1.9$ to 11.8 , $p=0.16$ ). We found that costs in those with inpatient palliative care consults in the last 12 months of life were higher by $\$ 10,394$ (95\% CI $\$ 5,575-\$ 15,213)$. When inpatient palliative care consult was added as an adjustment variable for both groups in the generalized linear model, we found costs were $-\$ 8,963(95 \% \mathrm{CI}-\$ 15,411$ to $-\$ 2,515)$ in ACPs versus controls.

From a program development perspective, the ACP program, including costs to train facilitators and time spent in facilitation, had a beneficial effect during the study period. The ACP program spent $\$ 1,515,170$ in intervention and execution costs in the community, and generated $\$ 3,087,500$ savings in Medicare expenditure in our sample. The net cost saving was $\$ 1,572,330$ and resulted in a $104 \%$ ROI (Table 3).

\section{Discussion}

We found that ACP was associated with an increased completion of HCPOA and POLST documentation. It is our hope that the AD documents reflect the outcome of rich facilitated discussions with patients and family. The primary effect is to engage patients and families in meaningful conversations that help relieve their anxiety and improve shared decisionmaking. We stress that any savings in utilization or costs with ACP should be viewed as a positive externality or side effect of ACP. From an ethical perspective, ACP holds with core concepts of respect for autonomy, beneficence, and justice. ${ }^{33}$ Also, in the case of our system, ACP also aligns with the Ethical and Religious Directives of Catholic Healthcare Services. ${ }^{34}$

Our results with regard to ACP and documentation rates are consistent with a recent systematic review without metaanalysis by Brinkman-Stoppelenburg et al., which found a positive impact of $\mathrm{ACP}$ on $\mathrm{AD}$ completion rates and compliance with end-of-life wishes. ${ }^{10}$ Past studies have included a prospective randomized effort by Detering et al. who found $18 / 154(11.6 \%)$ elderly patients assigned to the ACP arm had surrogates designated pre-ACP versus 56/154 (36.4\%) post-ACP intervention. ${ }^{13}$ In a retrospective cohort study of 54 intervention and 108 control patients, Chen et al. found advance directives completed in $98 \%$ of their Palliative Care Homebound Program (includes ACP elements) versus 31\% of controls. ${ }^{23}$ Bischoff et al. studied 4399 patients through a combination of survey and Medicare data and found that ACP was associated with less risk for inhospital death, and in contrast to our findings, they noted a greater likelihood of hospice use. ${ }^{12}$

We found that overall costs were less by $\$ 9,500$. This was driven primarily by a reduction in inpatient utilization, and did not appear to be due to increased hospice service use. There are few randomized trials of the impact of ACP on overall costs. Molloy et al. studied the impact of ACP-like discussions surrounding ADs for nursing home residents in Canada, and found reductions in hospital days along with reduction in costs of CAD $\$ 1,748 .{ }^{35}$ Engelhardt et al. assessed the impact of care coordination and assisting with ADs in high-risk patients and found that six-month costs were lower by $\$ 4,172$, which did not reach statistical significance, but over $40 \%$ in both groups were alive at study conclusion. ${ }^{36}$ The SUPPORT trial, ${ }^{37}$ which included telephonic end-of-life counseling by nurses, was secondarily analyzed by Hamlet et al. who found Medicare costs were $\$ 1,913$ lower in the intervention group in the last six months of life. ${ }^{38}$ The SUPPORT trial itself included ACP-like elements and did not show improvements in the incidence of DNR orders, ICU utilization, or inpatient costs. ${ }^{37}$

Various authors have found that inpatient palliative care consultation is cost effective. ${ }^{19,20}$ We found a higher number of consults in our ACP group, but this did not reach statistical significance. ACP may lead to more inpatient palliative care consultation or willingness to accept an offer of palliative consultation, which in turn may reduce inpatient LOS and thus utilization. While we cannot draw conclusions about the impact of inpatient consultation, those costs are captured for both groups. With regard to outpatient care, our system began 


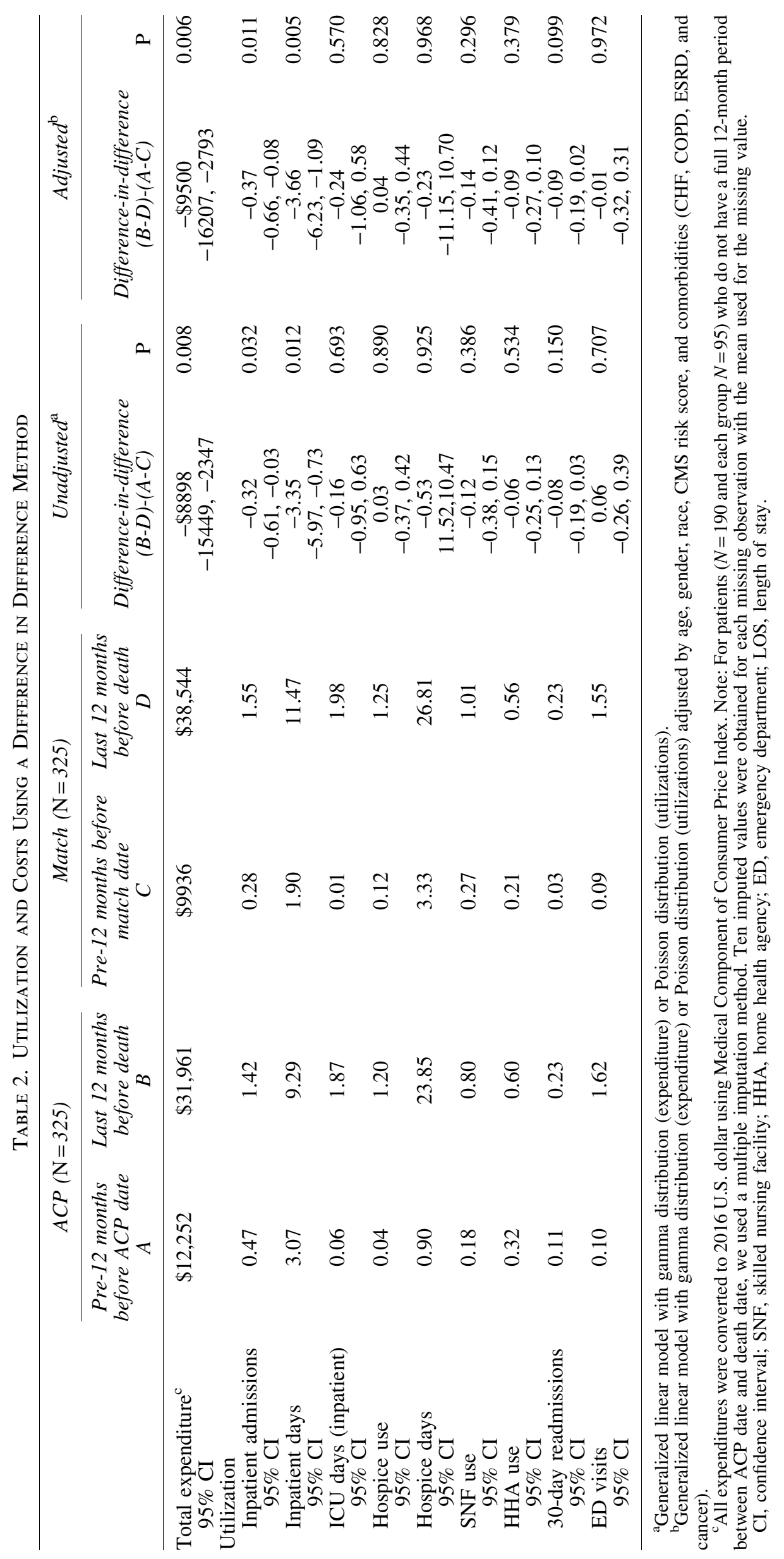


TABle 3. Return On InVESTMEnT

\begin{tabular}{|c|c|c|c|c|c|c|}
\hline & & 2013 & 2014 & 2015 & $2016^{\mathrm{a}}$ & Total \\
\hline \multicolumn{7}{|l|}{ Cost of ACP } \\
\hline Education program cost $(\$)^{\mathrm{b}}$ & A & $\$ 43,980$ & $\$ 42,932$ & $\$ 56,791$ & $\$ 18,237$ & $\$ 161,941$ \\
\hline Number of ACPs done (person) & B & 4672 & 3985 & 4448 & 1489 & 14,594 \\
\hline Weighted average cost per ACP $(\$)^{\mathrm{c}}$ & $\mathrm{C}$ & & & & & $\$ 29.54$ \\
\hline Execution cost $(\$)$ & $\mathrm{D}=\mathrm{B} \times \mathrm{C}$ & & & & & $\$ 431,107$ \\
\hline Maintenance cost of program $(\$)$ & $\mathrm{E}$ & $\$ 120,054$ & $\$ 159,047$ & $\$ 155,015$ & $\$ 49,282$ & $\$ 483,398$ \\
\hline Start-up cost (\$) & & & & & & $\$ 438,724$ \\
\hline Total ACP intervention cost $(\$)$ & $\mathrm{G}=\mathrm{A}+\mathrm{D}+\mathrm{E}+\mathrm{F}$ & & & & & $\$ 1,515,170$ \\
\hline \multicolumn{7}{|l|}{ Benefit of ACP } \\
\hline $\begin{array}{l}\text { Reduced expenditure of last } 12 \text { months } \\
\text { of life per patient (\$) }\end{array}$ & $\mathrm{H}$ & & & & & $\$ 9,500$ \\
\hline Number of patients died (person) & I & & & & & 325 \\
\hline Total benefit of ACP intervention (\$) & $\mathrm{J}=\mathrm{H} \times \mathrm{I}$ & & & & & $\$ 3,087,500$ \\
\hline \multicolumn{7}{|l|}{ ROI } \\
\hline Total cost $(\$)$ & $\mathrm{K}=\mathrm{G}$ & & & & & $\$ 1,515,170$ \\
\hline Net benefit (total benefit-total cost) $(\$)$ & $\mathrm{L}=\mathrm{J}-\mathrm{K}$ & & & & & $\$ 1,572,330$ \\
\hline ROI & $\mathrm{M}=(\mathrm{L} / \mathrm{K}) \times 100$ & & & & & $104 \%$ \\
\hline
\end{tabular}

a 2016 is a partial year of January-April.

${ }^{\mathrm{b}}$ Education costs increased slightly with the addition of simulation.

${ }^{\mathrm{c}}$ Weighted average costs reflect that the majority of ACPs were facilitated by nurses and social workers. ROI, return on investment.

a small outpatient palliative care services operational phase in January 2016. Thus, it is unlikely this service had a large impact on the data presented.

Our study limitations include its retrospective correlative nature, which cannot determine causal relationships. Specifically, many unmeasured variables such as family support, socioeconomic status, and others could influence the choice to seek or access ACP, as well as the outcome variables of choosing to create advance directives or less resource-intense care. The ACP cohort was more ill than the control group pre-ACP and the process of being offered an ACP is likely biased in favor of more ill patients. This bias may occur through factors known to the referring individual prospectively, but not available to a regression model using retrospective data. However, using the difference-in-difference method helps account for this bias. The data revealed geographic variation in the cohorts, with the control group being slightly more urban. This could also have impacted both the predictor variable through access to ACP and the outcome variables. In studying the raw data, we found some regional variation in hospice use, but this did not impact our mean differences.

Minorities are not well represented in our data set, which threatens external validity in a more diverse population. While our data are limited to one healthcare system, the system is broad in scope and services, and the facilitated ACP process used by our system is in keeping with the recent consensus definition ${ }^{7}$ as well as other facilitated models. ${ }^{39}$ Our study captured very few cancer patients. This may be an artifact of the coding of diagnoses that were pulled in an automated manner from billing data. We did not see differences between groups that would affect our comparison. Still, this limits our ability to draw conclusions about the impact of ACP on cancer patients. Lack of ACP in cancer patients may reflect that less ACP is being done in cancer patients, ${ }^{40}$ or that it is done in the cancer center context separate from our system's electronic health record.

As we consider the ROI for developing an ACP program, many noneconomic benefits accrue to patients and families, while the cost savings we measured accrue at the system (in shared risk), insurer (Medicare), and society level (in the case of publicly funded Medicare). We believe our ROI is a conservative estimate, given that uncaptured non-Medicare or Medicare non-ACO patients may have benefited during the same period of study. There are over 55 million Medicare beneficiaries $^{41}$ with a death rate of $4.45 \%$ as of $2013^{42}(2.45$ million annual decedents); thus, even small savings could be significant for the U.S. healthcare system.

Our conclusions are that ACP is a valuable service for patients and families, associated with improved documentation of patient's surrogates and choices, as well as reduced utilization and costs of care.

\section{Acknowledgments}

The authors wish to thank Mark Hohulin and Bryan Kaiser for early support in data acquisition, Jinma Ren for early design support, and Karen Renken, Jessica Fish, Kyle Mou, and Rebecca Ebert-Allen, for data acquisition.

\section{Author Disclosure Statement}

No competing financial interests exist.

\section{References}

1. IOM (Institute of Medicine): Dying in America: Improving Quality and Honoring Individual Preferences Near the End of Life. Washington, DC: The National Academies Press, 2014.

2. May P, Normand C, Morrison RS: Economic impact of hospital inpatient palliative care consultation: Review of current evidence and directions for future research. J Palliat Med 2014;17:1054-1063.

3. Penrod JD, Deb P, Luhrs C, et al.: Cost and utilization outcomes of patients receiving hospital-based palliative care consultation. J Palliat Med 2006;9:855-860. 
4. Heyland DK, Barwich D, Pichora D, et al.: FAilure to engage hospitalized elderly patients and their families in advance care planning. JAMA Inter Med 2013;173:778-787.

5. Silveira MJ, Kim SY, Langa KM: Advance directives and outcomes of surrogate decision making before death. $\mathrm{N}$ Engl J Med 2010;362:1211-1218.

6. Emanuel LL, Danis M, Pearlman RA, Singer PA: Advance care planning as a process: Structuring the discussions in practice. J Am Geriatr Soc 1995;43:440-446.

7. Sudore RL, Lum HD, You JJ, et al.: Defining advance care planning for adults: A consensus definition from a multidisciplinary Delphi panel. J Pain Symptom Manage 2017; 53:821-832 e1.

8. Chen CY, Thorsteinsdottir B, Cha SS, et al.: Health care outcomes and advance care planning in older adults who receive home-based palliative care: A pilot cohort study. J Palliat Med 2014;18:38-44.

9. Kerr CW, Tangeman JC, Rudra CB, et al.: Clinical impact of a home-based palliative care program: A hospice-private payer partnership. J Pain Symptom Manage 2014;48:883-892.e1.

10. Brinkman-Stoppelenburg A, Rietjens JA, van der Heide A: The effects of advance care planning on end-of-life care: A systematic review. Palliat Med 2014;28:10001025 .

11. Hammes BJ, Rooney BL, Gundrum JD, et al.: The POLST program: A retrospective review of the demographics of use and outcomes in one community where advance directives are prevalent. J Palliat Med 2012;15:77-85.

12. Bischoff KE, Sudore R, Miao Y, et al.: Advance care planning and the quality of end-of-life care in older adults. J Am Geriatr Soc 2013;61:209-214.

13. Detering KM, Hancock AD, Reade MC, Silvester W: The impact of advance care planning on end of life care in elderly patients: Randomised controlled trial. BMJ 2010; 340:c1345.

14. Advance Care Planning: ICN 909289. August 2016 Report from: Center for Medicare and Medicaid Services (CMS), Department of Health and Human Services (HHS), Medicare Learning Network (MLN). www.cms.gov/Outreachand-Education/Medicare-Learning-Network-MLN/MLN Products/Downloads/AdvanceCarePlanningText-Only.PDF. (Last accessed March 1, 2017).

15. Hickman SE, Unroe KT, Ersek MT, et al.: An interim analysis of an advance care planning intervention in the nursing home setting. J Am Geriatr Soc 2016;64:23852392.

16. Abel J, Pring A, Rich A, et al.: The impact of advance care planning of place of death, a hospice retrospective cohort study. BMJ Support Palliat Care 2013;3:168-173.

17. Nicholas LH, Langa KM, Iwashyna TJ, Weir DR: Regional variation in the association between advance directives and end-of-life Medicare expenditures. JAMA 2011;306:14471453.

18. Teno JM, Gozalo PL, Bynum JP, et al.: Change in end-oflife care for Medicare beneficiaries: Site of death, place of care, and health care transitions in 2000, 2005, and 2009. JAMA 2013;309:470-477.

19. Morrison RS, Penrod JD, Cassel JB, et al.: Cost savings associated with U.S. hospital palliative care consultation programs. Arch Intern Med 2008;168:1783-1790.

20. Penrod JD, Deb P, Dellenbaugh C, et al.: Hospital-based palliative care consultation: Effects on hospital cost. J Palliat Med 2010;13:973-979.
21. Brumley R, Enguidanos S, Jamison P, et al.: Increased satisfaction with care and lower costs: Results of a randomized trial of in-home palliative care. J Am Geriatr Soc 2007;55:993-1000.

22. Cassel BJ, Kerr KM, McClish DK, et al.: Effect of a homebased palliative care program on healthcare use and costs. J Am Geriatr Soc 2016;64:2288-2295.

23. Chen CY, Thorsteinsdottir B, Cha SS, et al.: Health care outcomes and advance care planning in older adults who receive home-based palliative care: A pilot cohort study. J Palliat Med 2015;18:38-44.

24. Kerr CW, Donohue KA, Tangeman JC, et al.: Cost savings and enhanced hospice enrollment with a homebased palliative care program implemented as a hospiceprivate payer partnership. J Palliat Med 2014;17: 1328-1335.

25. Lustbader D, Mudra M, Romano C, et al.: The impact of a home-based palliative care program in an Accountable Care Organization. J Palliat Med 2017;20:23-28.

26. Campbell DEP, Lynn JMD, Louis TAP, Shugarman LRP: Medicare program expenditures associated with Hospice use. Ann Inter Med 2004;140:269-277.

27. Gozalo P, Plotzke M, Mor V, et al.: Changes in Medicare costs with the growth of Hospice care in nursing homes. $\mathrm{N}$ Engl J Med 2015;372:1823-1831.

28. Kelley AS, Deb P, Du Q, et al.: Hospice enrollment saves money for Medicare and improves care quality across a number of different lengths-of-stay. Health Aff (Project Hope) 2013;32:552-561.

29. Klingler C, in der Schmitten J, Marckmann G: Does facilitated Advance Care Planning reduce the costs of care near the end of life? Systematic review and ethical considerations. Palliat Med 2016;30:423-433.

30. Center for Medicare and Medicaid Services (CMS) Financial and Beneficiary Assignment Specifications: www .cms.gov/Medicare/Medicare-Fee-for-Service-Payment/ sharedsavingsprogram/Financial-and-Assignment-Specifications .html (Last accessed August 15, 2017).

31. Bond WF, Gonzalez HC, Funk AM, et al.: Deliberate practice with standardized patient actors and the development of formative feedback for Advance Care Planning facilitators. J Palliat Med 2017;20:631-637.

32. Deyo RA, Cherkin DC, Ciol MA: Adapting a clinical comorbidity index for use with ICD-9-CM administrative databases. J Clin Epidemiol 1992;45:613-619.

33. Childress JF, Beauchamp TL: Principles of Biomedical Ethics, 7th ed. Oxford, United Kindom. Oxford University Press, 2012.

34. Ethical and Religious Directives for Catholic Health Care Services: United States Conference of Catholic Bishops, 5th ed. 2009, pp. 1-43.

35. Molloy DW, Guyatt GH, Russo R, et al.: Systematic implementation of an advance directive program in nursing homes: A randomized controlled trial. JAMA 2000;283: 1437-1444.

36. Engelhardt JB, McClive-Reed KP, Toseland RW, et al.: Effects of a program for coordinated care of advanced illness on patients, surrogates, and healthcare costs: A randomized trial. Am J Manag Care 2006;12:93-100.

37. A controlled trial to improve care for seriously ill hospitalized patients: The study to understand prognoses and preferences for outcomes and risks of treatments (SUPPORT). The SUPPORT Principal Investigators. JAMA 1995;274:1591-1598. 
38. Hamlet KS, Hobgood A, Hamar GB, et al.: Impact of predictive model-directed end-of-life counseling for Medicare beneficiaries. Am J Manag care 2010;16:379-384.

39. Hammes B, Briggs L: Respecting Choices: Advance Care Planning Facilitator Manual-Revised. La Crosse, WI: Gundersen Lutheran Medical Foundation, 2007.

40. Dow LA, Matsuyama RK, Ramakrishnan V, et al.: Paradoxes in Advance Care Planning: The complex relationship of oncology patients, their physicians, and Advance Medical Directives. J Clin Oncol 2010;28:299-304.

41. Total Number of Medicare Beneficiaries: State Health Facts. Menlo Park, CA: Kaiser Family Foundation, 2015.
42. Krumholz HM, Nuti SV, Downing NS, et al.: Mortality, hospitalizations, and expenditures for the medicare population aged 65 years or older, 1999-2013. JAMA 2015;314:355-365.

Address correspondence to: William F. Bond, MD, MS Jump Simulation OSF HealthCare $1306 N$ Berkeley Avenue Peoria, IL 61603

E-mail: william.bond@osfhealthcare.org 


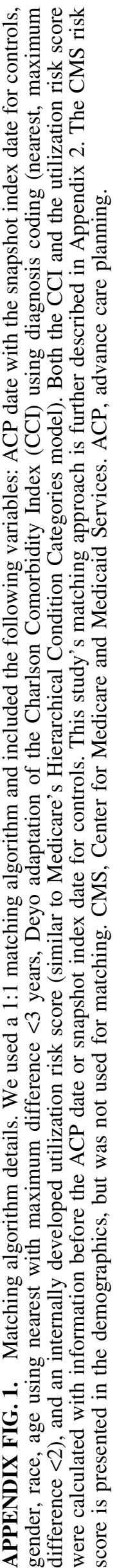




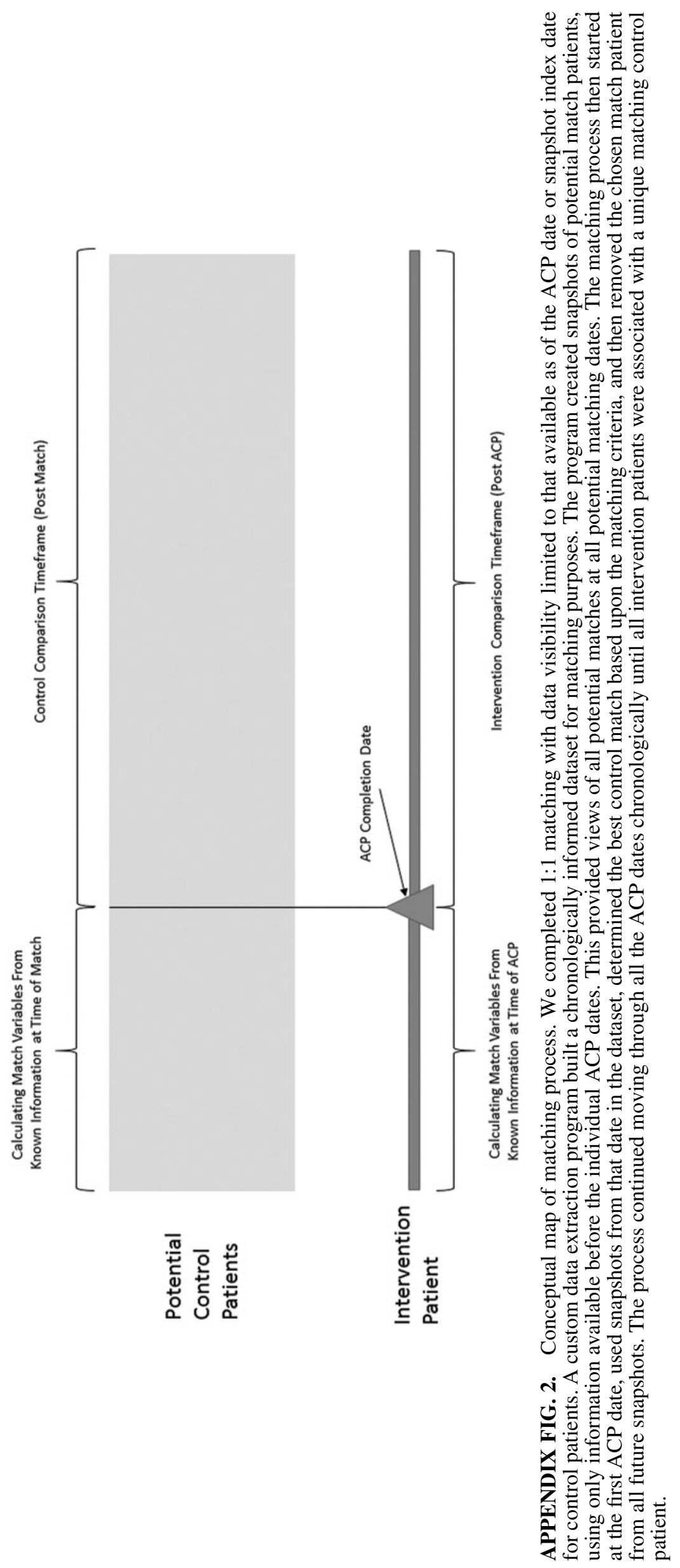




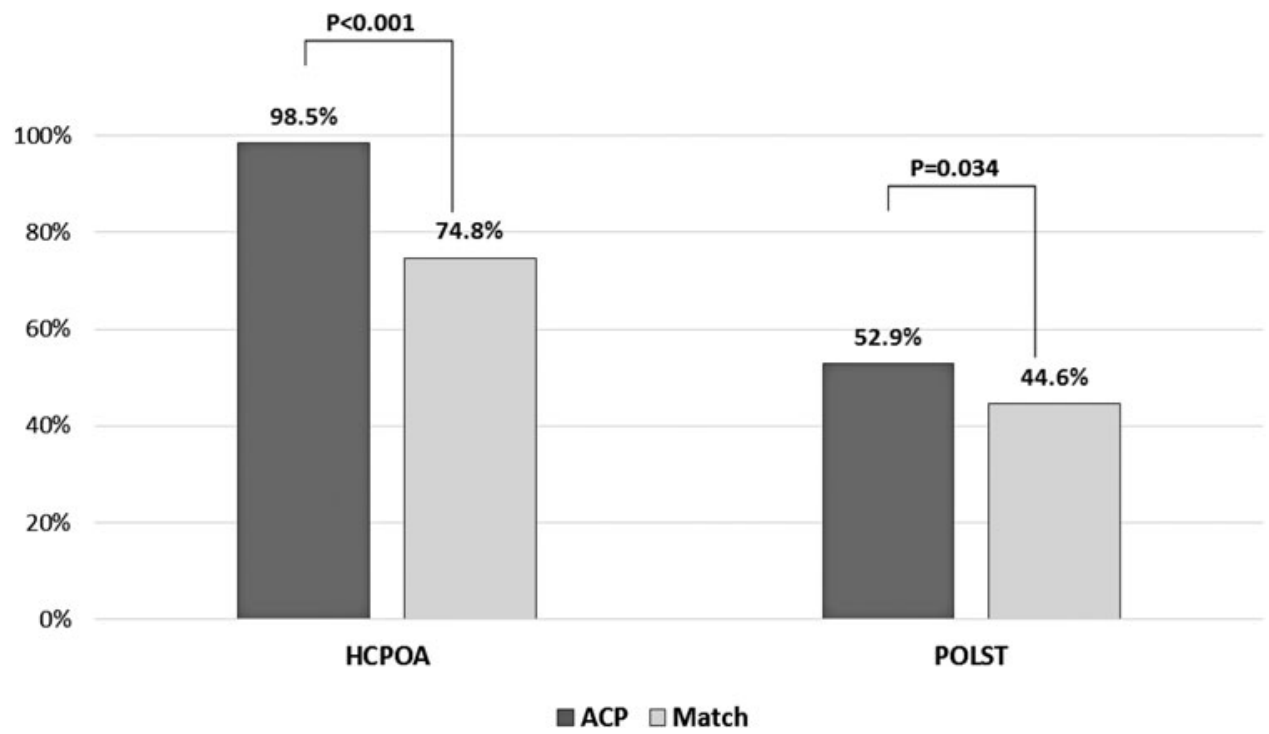

APPENDIX FIG. 3. In the twelve months prior to death, the proportion of Health Care Power of Attorney (HCPOA) and Practitioner Orders for Life Sustaining Treatment (POLST). 


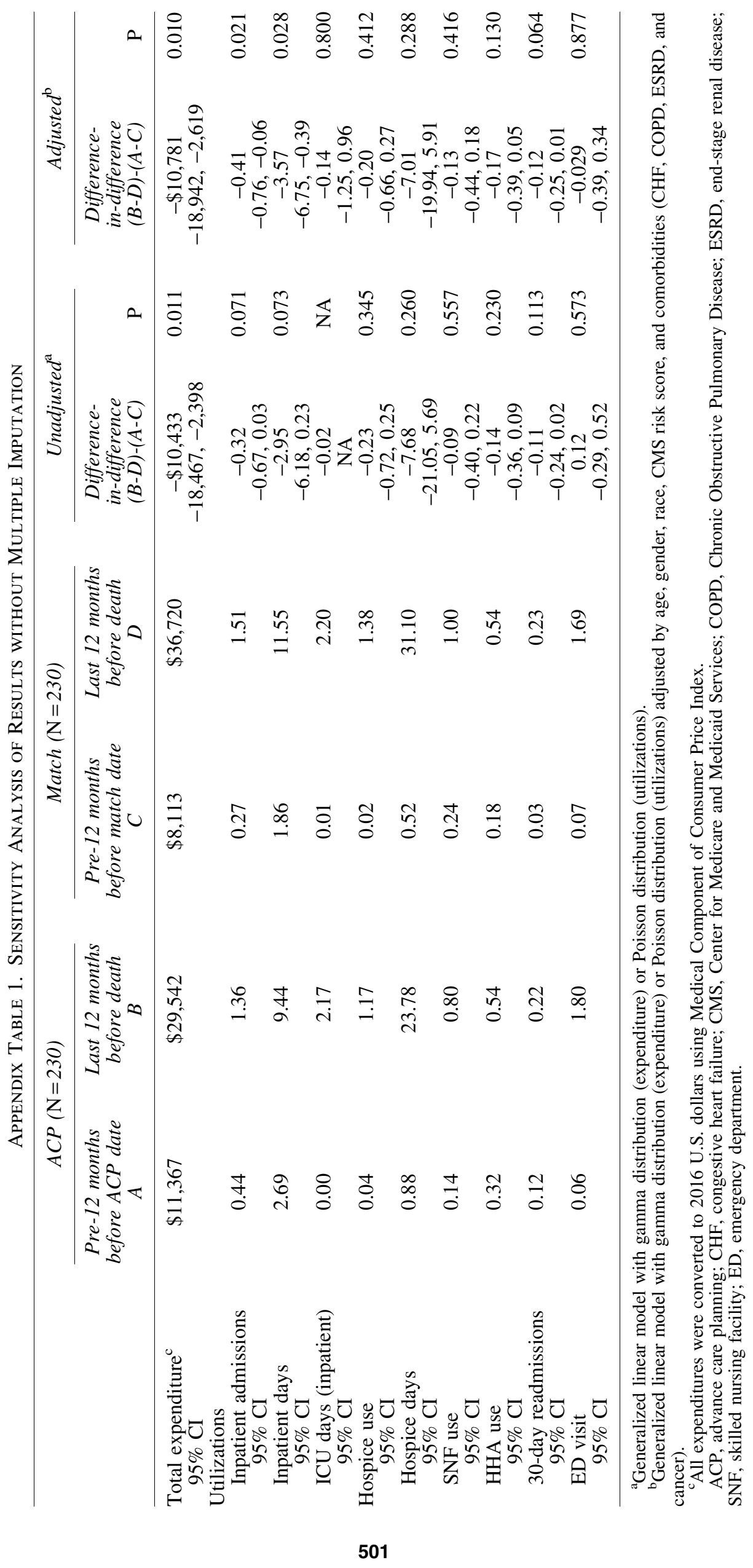




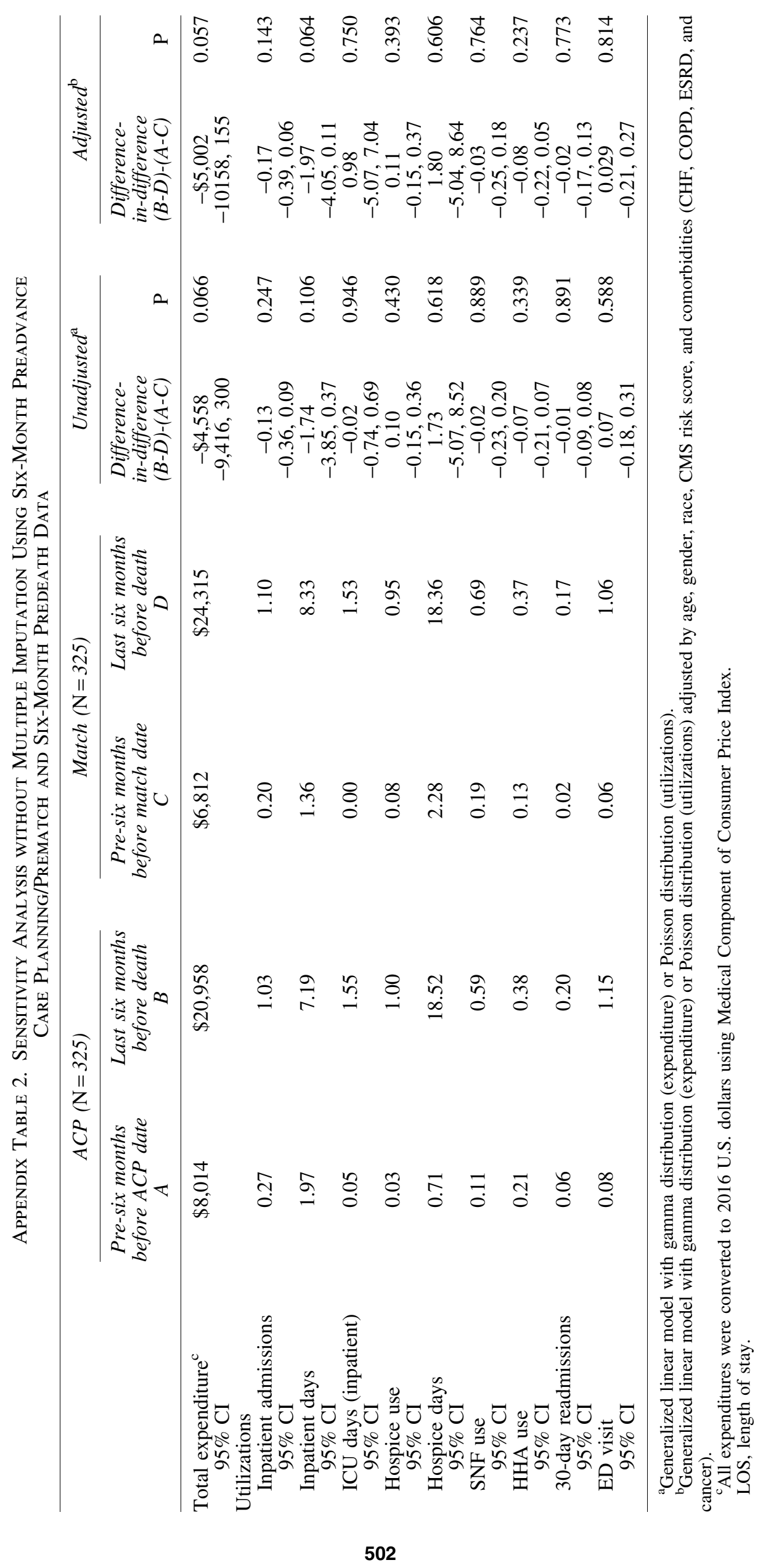

